\title{
The Final Cut?: The Production of pedagogy and scholarship within a society of control
}

Erin Adams, Bagwell College of Education, Kennesaw State University, e-mail eadams55@kennesaw.edu Stacey L. Kerr, St. Jude School, email kerr.s@stjudebulldogs.org; Xavier University, email kerrs@xavier.edu

Elizabeth Ann Wurzburg, College of Education, University of Georgia, email wurzburg@uga.edu

\begin{abstract}
In this article, we explore the teaching of post-qualitative methodology within what Deleuze called a "Control Society." We offer up the online video series Three Minute Theory, specifically the video What are Societies of Control? as an example of our engagement with post-qualitative theories and methodologies. We posit that post-qualitative methodology repurposes the tools of a control society and for that reason is both needed and necessary for making sense of the world we live in. In the article, we provide "outtakes" from the video script that serve to illustrate the process of producing a pedagogical product, highlights our collaborative writing process, and provides additional examples of control societies. Then, we discuss our pedagogical considerations when making the video, including the importance of current-day examples and the creation of a "writerly text" that would allow our audience/students to use as an impetus for creation rather than as a source to be reproduced. Finally, we provide examples of the ways in which post-qualitative methodologies align with control societies and the possibilities this presents for researchers.
\end{abstract}

Keywords: Post-Qualitative Research, control societies, surveillance, Deleuze

\section{Beginnings}

In the Spring of 2013, while pursuing doctoral degrees in education, the three of us took a new qualitative research course being offered in our department called "New Materialisms/New Empiricisms." Elizabeth St. Pierre designed the course which featured guest lecturer, Bronwyn Davies. It 
was in this course and through the completion of this collective biography that the three of us decided to form a writing group and to forgo the traditional qualitative sequence of coursework being offered by our college that would lead to a certificate in qualitative methodology and which would set us up with potential teaching positions in the field of qualitative research methodology. Inspired by Deleuze and Guattari (1972/2009), we decided to turn away from asking the traditional qualitative question of "what does it mean" to pursue the post-qualitative question "what does it $d o$ ". In particular, making this turn involved "thinking with theory" (Jackson \& Mazzei, 2012). Thinking with theory to us became as much of a qualitative methodology as others traditional qualitative methods like interviews and coding. In particular, thinking with theory functions as a method that "plugs in" (p. 4) theoretical concepts alongside texts (data) in order to make new connections. Thus, we decided to pursue theory on the way to a methodology-to-come; post-qualitative research.

In our desire to do something new in qualitative research and teacher education, we took a wide range of courses on diverse topics including: post-structuralism, feminism, Marxism, Foucault, rhetoric, geography of thought, sovereignty, critical geography and education, and a special course on Deleuze and Guattari's (1980/1987) A Thousand Plateaus. We were constantly working to understand and deploy the complex theories (new materialisms, post-humanisms, and post-structural theories) that frame post-qualitative methodology. Moreover, we struggled with the question of how to learn, think, do, and then teach (ourselves and others) something new, asking the quintessential question "how do we navigate experimental research practices that, in opening up new ontologies and ways of being, are often unintelligible to the very practitioners and fellow researchers with whom we hope to engage?" (Mazzei \& Smithers, 2020, p. 102). We knew that we would have to learn theoretical concepts, think with them, and explain them pedagogically in a way that our various audiences (our committee members, academics, other graduate students, friends, and family) could understand.

\section{Three Minute Theory}

Since 2014, we have made voice-over videos called Three Minute Theory, that aim to explain theoretical ideas in three-minute segments (Wurzburg, Kerr, \& Adams, 2020). The videos were intended to appeal to graduate students like us as well as a general audience.

We collectively write the scripts and then use public-domain images to create a visual text. In the creation of these videos, we go through the iterative process of writing and rewriting a script, selecting images, and syncing music that can succinctly introduce viewers to ideas we struggled with in our initial foray into reading theory (e.g. neoliberalism, the rhizome, and intra-action). We have reached over 500,000 viewers from around the world who may use the videos to prompt their own new understandings, thoughts, and pedagogies. We began with the rhizome and continued on, with the video featured here Societies of Control, as our fourth installment.

In this article, we share how we made the video series Three Minute Theory, with particular emphasis on our video What are Societies of Control? We show how we put the concept of control societies to work, with particular emphasis on the process and the pedagogy involved in order to demonstrate the 
entanglement between theory, pedagogy, and idea generation. We contend that the control society Deleuze described in the early 1990s is the current social conditions under which education in its many forms takes place today (teaching, learning, researching, resisting). Our SoC video, its contents and its mobile vitality and virality, are made possible by the technological conditions of a control society. As we revisit the Google Document that serves as our archive of collective writings about control societies, we also interrogate the conditions of a control society, exploring specific ideas about openness, finality, and collectivity. Overall, this is an exploration of method(ology); that is, the doing of research, teaching, video production and meaning-making.

\section{Making SoC}

One of the reasons we like to share our process is because we have heard that some faculty have assigned video production (modelled on 3MT) as a course assignment in graduate courses. We know this because we have heard from those graduate students how difficult they find the task. People are often surprised by the number of pages required to create a three-minute video. While the final script is only about two pages in length, there are sixteen pages of single-spaced notes in our shared Google Document that housed our SoC script drafts, ideas, and commentary. These sixteen pages are the material witness to the amount of reading, writing, and thought that goes into understanding and then explaining a concept concisely and intelligibly. We were reminded of what Deleuze (1984/2007) said of his collaboration with Felix Guattari: "We began by reading a lot: ethnology, economics, linguistics, etc. That was our raw material" (p. 238). Our collaboration, and our work, was only possible through rigorous and extensive reading across many subjects inside and outside of our coursework. St. Pierre, Jackson, and Mazzei (2016) remind us that this type of "close reading is required, always required" ( $p$. 103). We took this to mean that should (re)read what we didn't understand and plug in what we did as part of rigorous scholarship process in the new materialisms.

\section{Evolution of thought and messy texts}

Here is the introduction to our Three Minute Theory video What are Societies of Control? (Kerr, Adams \& Pittard, 2015) (SoC hereafter):

In this edition of three-minute theory, we provide an entré into what philosopher Gilles Deleuze called "Societies of Control." This concept is useful in considering and questioning how control, freedom, and our orientation to control and freedom function within an increasingly interconnected, technological, and surveilled world. In its simplest articulation, societies of control can be understood as an evolving form of discipline that moves beyond enclosed structures and outward into a sophisticated network of entangled systems. We'll discuss that more in a moment, but first, let's briefly talk about Foucault's description of disciplinary societies

As these words are spoken the words "control" and "freedom" appear on the screen, moving from a simple binary to a tangled mess with the appearance of the word "technology." These words and images are what made the "final cut;" that is, the finished, final product that you see now. That video 
was our official introduction to the concept of societies of control (Deleuze, 1992; 1987/2007). The video's actual beginning, however, was much messier.

Although post-qualitative research celebrates the "messiness" of texts (Lather, 2007), what appears in publication, or in our case, video is highly stylized and edited for clarity and brevity. Here, we will show excerpts from the parking lot material that would normally be left hidden and unseen and eventually forgotten about and disposed of. To write this article, we went back to the Google Document, which we consider our data or raw material. We call this archive of used and unused material our "parking lot" because it is a space for our ideas to occupy until needed. Throughout this article, we will pull material from this parking lot and deposit it here in italics. The parking lot also contained production notes, which are both italicized and underlined. Occasionally, we would use red and blue ink to make changes stand out and to show a change in authorship. We have kept the formatting and spelling from our Google Document. The text below shows just how messy our work could get. It provides a glimpse into cothinking and co-writing as a pedagogical exercise as we tried to work out what we wanted to say and how we wanted to say it. We began with the polished introduction, but we will show the much messier process that led to this point.

In its simplest articulation, we might understand societies of control as an evolving form of discipline that moves outside of enclosed structures into a network of sophisticated, entangled systems(I really like this sentence). In which managers act as overseers of our work. instead....(we are our own "managers/" governmentality)in which we are no longer governed in our work (?) by inclosed structures (like the factory) with top-down management and overt surveillance. In the open systems we live in now, we are largely free of this type of disciplinary structure.... Or at least it might seem this at first glance. wh whe l? someone rephrase that. but you know what I mean?ha), and are instead, seemingly "set free" from its confines. With this new form of freedom though, comes new forms of discipline, which we'll

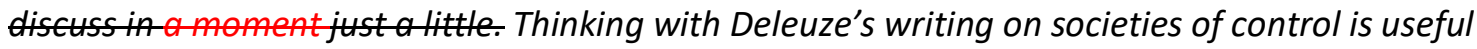
in considering and questioning how control, freedom, and our orientation to control and freedom function within an increasingly interconnected, technological, and surveilled world. (Love this last sentence)

This type of discipline created docile and compliant workers who (security cameras at red lights)

For this to make more sense though, let's first talk about Foucault's description of disciplinary societies - an idea upon which Deleuze extends and adds. OR--which is the starting point in Deleuze's theorizations of SOC

The above text shows an initial attempt at an introduction. First, we had to define a control society. Then we had to differentiate, for ourselves and our audience, the difference between an enclosed, factory-like disciplinary society that Foucault and others theorized and a more open, seemingly freer and more mobile control society. The text shows some production notes or suggestions that Stacey, who did the voice-over and put the images together, might include in the video. The text shows us crossing out, starting over (there are numerous introductions that never made the final cut), making comments and 
providing suggestions for visuals (in parentheses). You can see that the early text was simultaneously a conversation between the three of us as much as it was a script; we added little notes like "I love this" as well as comments like "someone rephrase....you know what I mean...ha." For us, writing together was playful and closely mirrored our in-person writing group sessions.

The parking-lot text also shows explanations that did not make the final cut. For example, "we are our own managers" wasn't necessarily meant to ever be in the final transcript but was an articulation to the group to explain a thought. This was what we wanted to say, our task was figuring out how to say it in the most efficient and effective way possible. Though utilized less frequently, we sometimes used the comment function in Google Documents. Here you can see us trying to define a control society and our struggle to use "potentially fewer words."

discipline and control would operate in an open system that would be simultaneously more controlling while also more freeing. Unlike the discipline system that is wholly predicatable, the only thing predictable in a control society is unpredictability. Sidebar comment from Authors (screenshots)

Image 1. Defining Soc

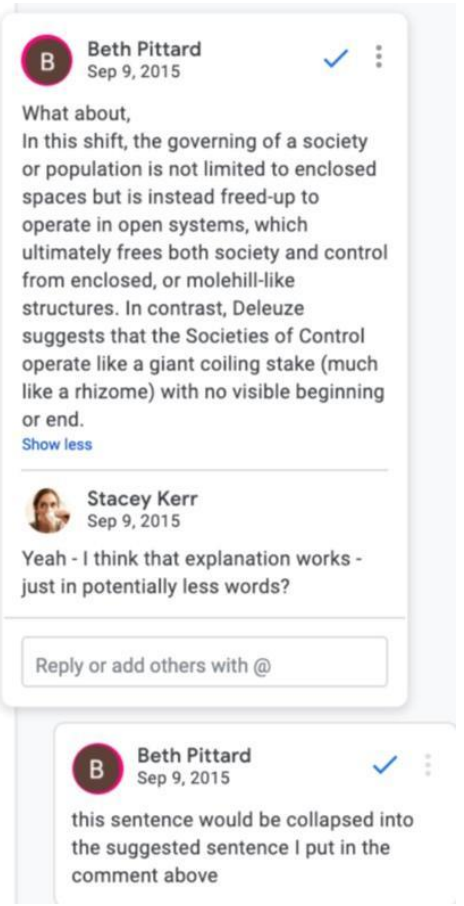

Brevity, as we show in this article, was a constant issue for us, but a challenge that we embraced as part of learning. 


\section{Collaborations and collectivity}

The videos were a collaboration that was "never a homogenization, but a proliferation, an accumulation of bifurcations, a rhizome" (Deleuze, 1984/2007, p. 239). Like a rhizome, it went in all directions and did not necessarily progress in a linear fashion with a clear introduction, body and conclusion. In other words, The Google Document did not make sense. Our writing and conversation(s) flowed freely, took tangents (or, following Deleuze, 'lines of flight') and oftentimes got stuck. It included hyperlinks to websites, other Google Documents, images, memes and videos. It was a dumping ground connected by threads. At one point, this Google Document became so overwhelming and full of ideas, the three of us put the project on hold for several months. We could not even look at the document and begin to organize it. Yet, when we returned to the Google Document, we found that our work was strengthened by the disconnections in disorganization that we could now see as our ability to collaborate and to have, in each other "a co-producer of thinking" (Van Cleave \& Bridges-Rhoades, 2013, p. 681). To echo the sentiments of another productive post-qualitative writing partnership, that was "so intertwined that it is impossible at times to determine who wrote any given sentence or even to tell whose reading of Foucault, for example, enabled that sentence" (Van Cleave \& Bridges-Rhoades, 2013, p. 674), our own work became entangled and intertwined with each other, "an authorly assemblage we have knotted together" (Zarabadi, Taylor, Fairchild and Moxnes, 2019, p. 106).

In the following section, we demonstrate the ways in which our conversations ran into each other, picking up where the last person left off and even where we ran up against different readings and understandings of Foucauldian and Deleuzian concepts. We show raw writing and data from writing sessions. However, sections are not attributed to an individual author, mostly because it is impossible to determine, both then and now, who wrote what.

\section{Analogies and examples}

In the script writing, we reached a point where we were ready to move away from Deleuze and Foucault's words and examples and move into new territory with new, 2015 examples. In each of our videos, we try to find a concrete example that can be threaded through the entire video. The following example shows us trying to find our example. We considered either biodata or smartphone. Notice how we write our way through the example, blending together our various readings and disciplines, folding together theory and our lived experiences;

Just think how attached many of us are to, for example, our smartphones. To lose the smartphone could mean losing vital information about the organization of one's life including schedules, passwords, (??). **Maybe there is another example--one I think is really provocative is bio data--it could be used in amazing ways to cure all sorts of diseases from diabetes to yet-tobe discovered viruses, but it also gives the holder of all of this bio data an enormous amount of power to do evil as well... like both of these examples. 
You can see us proposing both biodata and Smartphones as our example of a control society. Preparing this manuscript for publication, we cannot help but notice the prescient mention of viruses, which speaks to the ongoing relevance of control societies. It also makes us wonder if biodata would been a better choice. Ultimately, Smartphones made the final cut because;

Smartphone might be a more universally understandable concept and something, we may have fun playing around with b/c of its seemingly innocuous existence. I see how we're already caught up in the "coiling serpent" of the Smartphone. 10 years ago, a person would "upgrade" by getting a newer phone with more features every 2 years or so, progressing in a somewhat linear fashion based on both personal wealth and advancing technology. i.e. moving from basic cell phone $w /$ antenna to flip phone to sidekicks to the Smartphone revolution. But now that we have these Smartphones, we must constantly update them, get the newest apps, etc. It's a cycle we can't get out of b/c we have been conditioned to need it (how else would we find our way around, communicate with our friends, take photographs, etc?). We fear losing the phone (the phantom vibrations) and must be constantly aware of its existence. Now it's a new iteration of the same thing-an iPhone 3, 4, 5, 6, a newer version of the same product rather than an entirely new or unique product (just reminiscing about all the phones I've had over the years, all different brands, designs, functionality, etc). And it's through this Smartphone that much of this entrepreneuring of the self seems to happen (Foucault, 2004/2008). The Smartphone becomes the sacred object b/c of its ability to facilitate other relationships-with family and friends (i.e. communication, pictures, etc), with our bodies (fitness apps), with our surroundings/environment (weather app and GPS). They make our lives livable and yet also unlivable (b/c we can never really "get there" but are always trying). I read somewhere that NASA sent astronauts to the moon with as much technology as we have in our smartphones (i.e. we hold in our hands/pockets/handbags the knowledge capable of sending us to the moon). So, it's not like we have to crawl out of the darkness and into the light and attain knowledge, $b / c$ we already have it (the snake as knowledge like in the Adam and Eve story. it knows the secrets of creation). But a snake is slippery, and it must move constantly to survive (hopefully some of this makes sense. I'm writing this very late at night and it's probably a whole other project altogether).

Like all good concepts, once we read Deleuze's (1992) Postscript on societies of control in class, we began seeing the a/effects of a control society everywhere in our lives. The writing above shows our attempts to use these everyday insights as a way to introduce others to societies of control.

We made connections between seemingly unlike things; Genesis, cell phone plans, Plato, and NASA. Smartphones won out because it seemed like the thing that would be most relatable and needing the least amount of explanation (unlike biodata which is maybe not a word most people can define right away). The smartphone was able to embody many of Deleuze's examples of a control society; surfing (the Internet), snake (infinite and elusive), gas (the "cloud") and the highway (the Internet/information superhighway) as well as the warnings Deleuze provided about the ways such devices multiply mechanisms of control while also simulating freedom. 
As we revise this manuscript in 2020, we wonder if we were mistaken in choosing Smartphones as the most material and enduring example, especially since it has been rumored that Apple wishes to phase out the iPhone within ten years-something that seemed unfathomable in 2015 when the iPhone 6, and the SoC video, debuted. Of course, we also could not have known about intrusive home-technologies such as Alexa in 2015 either. Looking back now, we see how salient and enduring biodata would have been as an example and how it related to our previous video on neoliberalism:

in all areas of society such that capitalism is freed up to What does this mean? In short, it means (as it is theorized by Deleuze and Foucault) that w/in NL SOC nothing is sacred--except perhaps the almighty dollar. Ethics goes out the window via what Foucault called an "economic-ethical ambiguity." Nothing, including personal medical records (or bio data), ---, or --- is off limits from the exploitative capitalistic machine. In other words, whatever generates a profit--no matter how damaging to human dignity, livelihood, and even life itself--is validated through the "truth" of the market-ethic. The formerly closed-off institutions such as prisons, the military, healthcare and even schools are "freed up" for capture within capitalism's desiring machine.

****For example, (big data,--data banks that produce individuals as "dividuals") (modular metastable states, that transmute) (Adams, Pittard, \& Kerr, 2015)

In creating this manuscript, we remembered our biodata-smartphone debate, but we had forgotten about an early dabble in using millennial as our example, which we re-discovered at the very bottom of the parking lot (note the consistent misspelling).

one way we might hook our viewers is by using something fairly familiar-the plight of "millenials" and those un/fortunate enough to hire them (maybe i just have millenials on my mind $b / c$ we had to take a 'how millenial are you' quiz for the stupid teaching institute). These "characteristics" aren't just quirks of a niche generation but a group coming of age in post-cold war, neoliberal America that Deleuze and Foucault could see coming. By focusing on this group's so-called "characteristics" hides deliberate destabalizing mechanisms put into place. You might have heard about Millennials, those born and their job problem-namely a seeming lack of staying power. Blame it on too many video games, parents that were too lenient, or a sense of disillusionment or entitlement. Too much freedom, not enough control. After all, their parents and grandparents earned gold watches and retirement parties after thirty years on the job. Yet, something has changed. The gold watches and retirement packages have been traded in for iPhones and tablets and work from home. Job hopping has replaced longevity. And, while it could have something to do with those factors listed above, perhaps there has been a significant shift in society that philosophers such as Foucault and Deleuze glimpsed as early as (date).

The millennials commentary was accompanied by a link to a Forbes article on job-hopping. Again, we can see how Deleuze's concept was being put to work and helping us understand daily frustrations, such as Erin attending a work training where "those millennials" was hurled pejoratively and focused on 
individual character defects rather than systematic economic destabilization-the hallmark of control societies. The parking lot shows us writing our way through these and other problems.

These conversations also speak to what can be produced by free writing that is unconstrained by scholarly conventions. Since we had decided to produce a video of only three minutes, we could not put all of this into the script. Although we did not use this material in the script, this body of writing served an important purpose in clarifying our thoughts and rationalizing the smartphone as a metaphor to explain a society of control. Thus, although it wasn't "used" it was nonetheless useful. In control societies and the neoliberal institution, the only things that 'count' are those that can be counted, that which is final and finished. Therefore, people are constantly required to do more to prove their worth. For example, the final product, the SoC video, counts as scholarship, but our employers likely would not let us count our parking lot as scholarship; idea generation does not fit neatly as a citation on a CV. A journal editor would likely not publish it, as is, because the language is not "professional" and the organization is not linear. Revealing the workings of our video, we hope, reveals the hard intellectual and creative work of reading, writing and thinking necessary to produce the video so that this kind of labor is not discounted but viewed as a product of the productive.

\section{Negotiations and cuts}

As the above excerpts have shown we had an excess of material. To refine our ideas down to three minutes of concise explanation, we had to make many cuts. Making such cuts meant negotiations with ourselves and each other about what would go into the script. This cutting process also revealed some differences in our thought. Although we were working with largely the same source material, we approached it from slightly different theoretical orientations and directions that became substantive enough to warrant a pause and reconsideration. For example, the concept of governmentality and the extent to which people willingly participate in it, became a point of contention;

Interpersonal communications become much less private and freedom comes at the cost of this privacy. There may not be someone watching from tower like the disciplinary societies (show image of Panopticon) but things like location services and navigation systems, social media posts, browser histories, open records suits, credit card statements, and call logs all become ways the watchers watch and we, in turn, sometimes willingly (or even unknowingly participate) comply (<--But its not that simple, is it... We have to be careful not to characterize this as totalizing). In this compliance, we are governed and in an extension from the disciplinary society, we continue to govern ourselves and others. Foucault called this "governmentality". I don't think we can just throw this in there like that-we need to expand or cut it out. Maybe say: but they also have the potential to control the population at unprecedented levels through data-gathering capabilities such as the constant GIS tracking made available to cellphone network providers.

And it, of course, does not stop there.... 
These are awesome but we have no room for expanding though! Maybe this could be part of an accompanying blog post? I think we just have room to add a word or two or we have to cut that many other paragraphs. Saying those paragraphs out loud takes about 2 minutes itself.

Governmentality became an issue. First, it warranted more time and space than we had available. Second, we disagreed about how exactly governmentality happens and the extent to which it involves human will. While yes governmentality is about self-governing (which the openness of a control society only exacerbates), one author wanted to emphasize that we often, thinkingly or not, agree to the "terms and conditions" that offer up our bodies and lives to surveillance and datafiction. One of the other authors, however, warned that this was too totalizing and victimizing, while the third tried to write a sentence that got at both viewpoints. We decided to use this material for a different episode devoted to governmentality. This solved the first problem and temporarily solved the second one (at least for this episode). In the end, we tabled this discussion. However, we include it here and when we discuss our work because we think it is important to show how we disagree with each other and that what made the final cut was born of compromise as much as consensus and how we tried to choose our words and phrases carefully so that they would not be taken out of context (as much as this was something that we could control) and so that we would not confuse or isolate our audience. The examples given so far points to the challenges of having too much material and not enough time to work it in. We were making connections between the rhizome and neoliberalism, the topics of our previous videos, as well as trying to introduce new ideas and material. We developed several solutions to the timing problem, including using images, creating an open text, and saving material for a new video. These solutions are discussed in the next sections.

\section{(New)Images (of thought)}

One solution to the timing issue (we are committed to staying within three minutes) was to remember to use our images. We wrote the script first and Stacey put the visuals in last during the actual videomaking. Erin and Beth would make suggestions in parentheses such as (insert picture of smartphone here). Below is our conversation about leveraging the visuals as related to our ever-evolving conception about what societies of control are and how they work;

Well I also think this is where we utilize the visuals when we can-to make points we don't have the time to say. To me, that was the best thing about the rhizome video-those flashes of school kids, etc. I think we also have to be efficient $w /$ our examples and see what we're gonna get the most use out of-like the smartphone kind of encompasses so much of what SOC is aboutmobility, access, our daily lives, surveillance, navigation, social media, etc.

So far, we have focused on the written script and script notes. However, the visuals are crucial. They serve as another layer of "text" that is every bit as important as the written/spoken script. Take the series of images below, which show the way we demonstrated a movement away from closed to open markets; 
Figure 2. Car factory

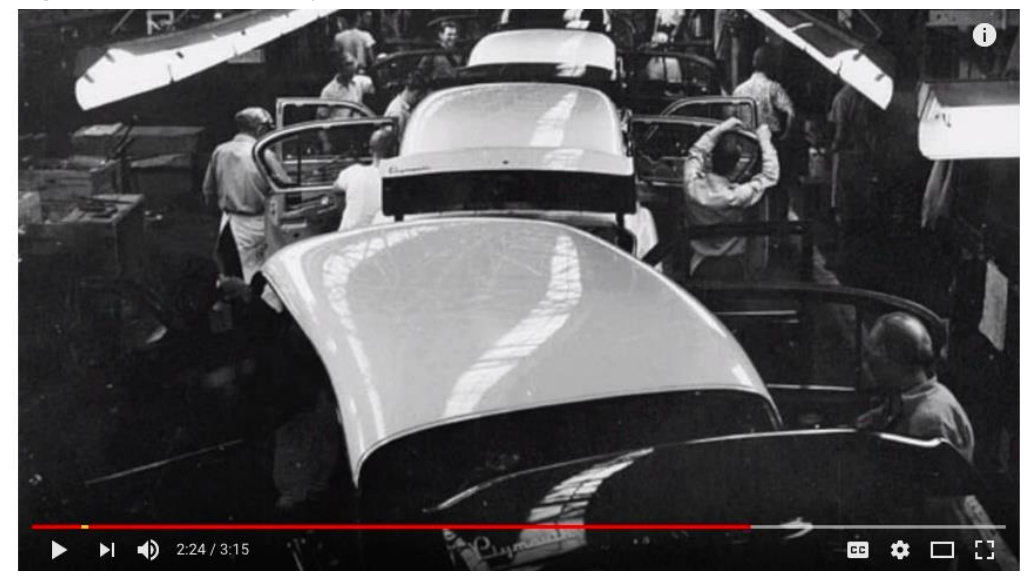

Figure 3. Mall

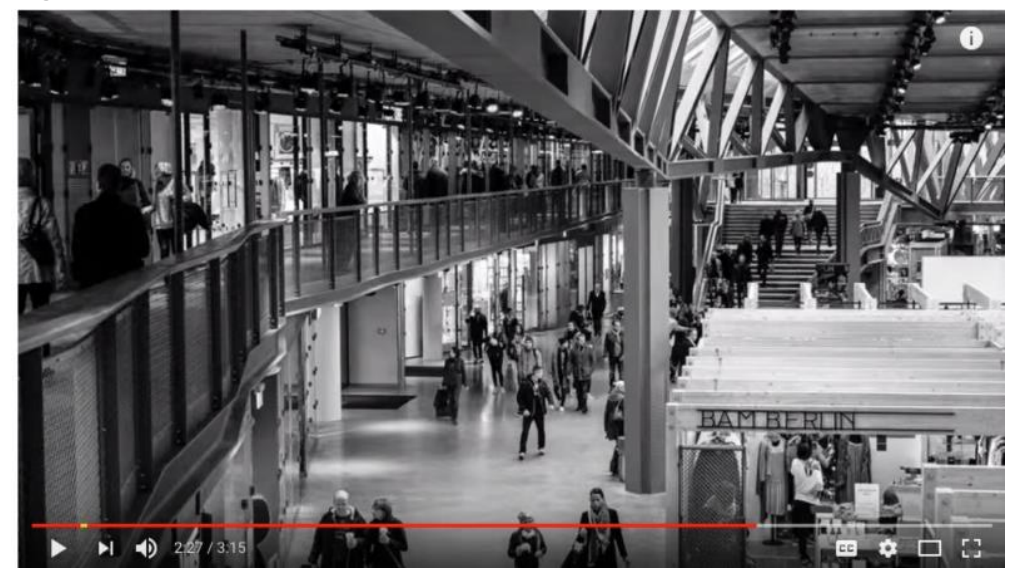

Figure 4. iPhone

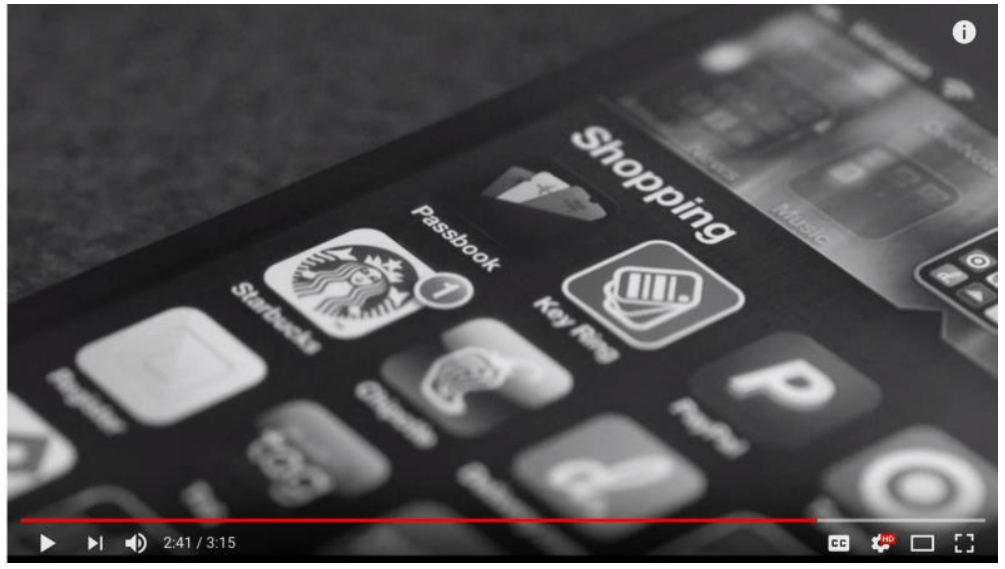

These images come at the point where we move away from a "vocabulary lesson" to examples that show (rather than tell) the progression from closed to increasingly open, technologically advanced, more 
mobile, and, perhaps, more individualistic societies. We hoped to capture this sense of hyperconnectivity and simultaneous loneliness through the images as well as the simultaneous feelings of freedom and control. Shopping, once a highly social activity requiring bodies to gather in particular spaces at particular times, is now a matter of downloading an app and then picking up or receiving the desired items at one's earliest convenience. Note how the apps on the phone in the image are able to convey much of our discussion on the diffusion of "control" without us having to provide extensive explanation. For example, that Starbucks app tracks the user, gathering incredibly personal data on the user's location, movements, spending, and eating and drinking habits. Ironically, the user actually gives up a great deal of privacy in this society which seems to offer personalization and privatization at every turn.

\section{Writerly text}

As we show in the text above from our conversation, we not only wanted to use images well, but we also wanted to treat the video as a primer and trust our audience to follow our reference list and make the intellectual leaps between ideas. Part of this was a practical move--to forgo extended as we have done here explanation for the sake of time. Another was because we wanted to provoke thought while resisting dogma. That is, we wanted to leave the text open enough for our audience to make their own meaning. Our goal was never to be authoritarian, but to present our interpretation and understanding while issuing an invitation to others to engage with us. This is part of the power of visuals and visual texts, "the film does not record images, or convey representation. It acts, it performs, as a 'body' with other bodies...through the affective" (Kennedy, 2000/2002, p. 102). We wanted our video to move, or affect, people. That is one reason we chose not to just summarize or repeat Deleuze's writings, but to insert our own examples to signify our insertion into the "text". In this way, we created a writerly text rather than a readerly text. Our discussion of this move towards a writerly text is shown below;

Plus we are trusting our audience to come away with questions and connections...so if we make an allusion to something it's their responsibility to think on it and flesh it out. To me, that's the difference btwn 3 minutes and an academic paper or something more explanatory ya! i dig it. ya - we can be really choosy with images to help support that. And i don't think we have to explain everything in detail. just keep it as prompts and they can allude as to what we might mean based on the video and then go read the thing themselves and see how they make sense of it with our primer on it.

For Barthes (1973/2002), a writerly approach to text breaks down the binary relationship between the author/reader or owner/customer in order to "make the reader no longer a consumer, but producer of text" (p. 4). Segall and Gaudelli (2007) advocate for the use of writerly texts in the teacher education classroom (text as both articles read and classroom pedagogy) because "students arrive[d] in our classes having acquired the skill to read a text without writing it" (p. 79). In other words, students most often could repeat a theorist's ideas while "avoiding implicating themselves in the text and vice versa" (p. 79). Barthes emphasized writerly texts as productive rather than representative "to rewrite the writerly text would consist only in disseminating it, in dispersing it within the field of infinite difference" (p. 5). We 
appreciate the intellectual challenge that Deleuze's writerly texts provide for us as ongoing students of his work and the ways we, and others, are then able to put them to work in new and different ways. As we have shown through our examples, theory is highly personal and particular concepts, such as societies of control, particularly resonated and we began to notice examples everywhere. Other people might see something different. We trust our audience to make the intellectual leaps necessary to make SoC a useful tool for themselves and their work.

\section{Freedom and Openness: Constraints that Enable(d)}

Images allowed us to convey our ideas while leaving most of what we actually wanted to say unsaid, thus reducing sixteen pages of script and ideas to just three pages. We resisted the urge to over-explain; leaving our explanation open enough to be "writerly" instead of passively "readerly." For example, we hope that our image of the smartphone apps inspired our viewers to take out their own devices and begin doing their own theorizing about the freedom and control at their fingertips and in their pockets. Moreover, although we suppose we could have made the video as long as we wanted (it was ours, after all) we ascribed to a theory of "constraints that enable." Drawn from Castro (2007) in art education, these are imposed constraints that "offer opportunities to create spaces of unimagined possibilities" ( $p$. 76). Because certain possibilities were restricted (for us it was more time), we were challenged to leverage our images and examples to the greatest e/affect. You can see us struggling with time in the conversation below and our repeated mantra that we wish to be a jumping-off point not a comprehensive lesson;

This is 3:30-3:50 depending on speed - and i'd rather speak slowly since $i$ know i tend to talk fast anyway. HA! So we need to maybe cut a tiny bit. But almost there. and if something crucial needs to be added, we'll have to select something to take out. I like what's been done! this is a hard topic b/c there's so many ways to approach it... I like the subtle key words and references, like $D \& P$, in here, as we want to direct $p p l$ to find more and read more on their own.

Although it was more challenging to stick with three minutes (rather than four or five or even twenty) we think it made for a better product. As we've stated before, the video is both an explanation of, and product of, a control society. The control society's emphasizes technology and demands open-access learning materials. A control society also is also characterized by attention competition. Pragmatically, we know that three minutes might be just right for people's attention spans considering the myriad of other options available for consumption ${ }^{1}$ in the openness that is the Internet. Furthermore, we chose to see these constraints as freeing, and, in doing so, as a small act of resistance against a control society of (seemingly) infinite openness in terms of time and space. In a society of more, we actually chose less.

\section{Doing post-Qualitative research in a society of control}

We hope that seeing our production process has been helpful in considering elements that go into making an effective teaching tool. We hope that seeing our rough drafts and conversations has helped

\footnotetext{
${ }^{1}$ We've seen other, much longer, videos about Deleuze and control societies available on YouTube. 
add to an understanding of societies of control. We think that this understanding is important because, if we live in a society of control, then we need methodologies that can help untangle, for the time being at least, the complexities of doing research in ever-increasingly "entangled systems" that are highly technological (Barad, 2007). Traditional qualitative methodological attempts to enclose, deepen, humanize, code, validate and know through prescriptive methodology (mole-hills) seems at odds with today's societal posts-human(isms), truth, structural, modern. Post-qualitative methodology allows for research that is flexible, slippery, un/coded but highly theorized in order to make sense of a world that increasingly eludes our senses, our knowledge, ourselves. In the following sections, we discuss key aspects of societies of control; technology, snake/surfing metaphors and professionalism, that are significant to doing qualitative research.

\section{Technology}

Technology and mobility are key, co-constituted aspects of control societies. Technology epitomizes the nature of work in a society of control and mobility is indicative of the spaces where this work takes place. We designed the Three Minute Theory videos to meet graduate students, and others, where they were, in whatever stage of scholarship and location they found themselves. Lather (2013) described "Qual 4.0" similarly "in this methodology-to-come, we begin to do it differently wherever we are in our projects" (p. 635). Thus, we created a pedagogical tool that was not confined to the enclosure of the classroom or course or program of study. YouTube and social media outlets such as Facebook and Twitter allowed us to disseminate the videos to a wide and diverse audiences. For us, smartphones and laptops are not just useful examples. They work as the mechanism with which SoC could be produced, viewed, disseminated, shared and discussed. For these reasons, we think that Deleuze's description of a society of control can inform the context of post-qualitative research and the reasons post-qualitative research seems appropriate and timely in attending to the lived and unlived experiences of the phenomena we are attempting to understand.

\section{Technology and data}

We have reiterated here and, in the video, how important technology is to the production and reification of control societies. Technology produces post-qualitative work. Of course, researchers have always used devices for word processing. In our work, technology was not external to the study itself. We used smartphones to take audio and video recordings, to make appointments with participants, and to find our way to the different research sites (such as schools, grocery stores, coffee shops) that we utilized. The smartphone made our research mobile, not confined to particular enclosures. The participants in our research projects also used smartphones to do their work in co-constituting, or generating data, including; setting up appointments, making lists, pinning to Pinterest, making maps, taking pictures, creating videos. Our data were not outside of the device that made them (possible). It didn't merely help us collect data, it was our data, it produced, or created data.

\section{New questions}

The role of smart technology also raises new and important questions for qualitative research. Namely, when does research begin and end? When are the research participants "on" and "off"? What is our 
duty and responsibility to participants after the project's "end" date? Are we still (Facebook) friends or (Twitter) followers or text messages? What counts as data? I know that data is constructed, but did "I" make this data? Hence, in diffusing and "opening" up the contexts in which we research in, a society of control, and smartphones, blur the lines and breakdown the binaries of researcher/participant/friend, beginning/end, theory/method, self/other, human/nonhuman, data/anecdote, for example and also raises new, ethical questions for post-qualitative researchers to answer. Karen Barad, for example, articulates a vision of ethics that is about openness, an ethics that is "not a calculation of value or utility, but an infinite responsiveness" with/in an open system (deFreitas, 2017, p. 745) in which all are implicated and response-able, what Barad (2012) called a "queering of responsibility" (p. 81).

\section{Go with the flow: Snakes and Surfing}

We think Deleuze's metaphors of sports/surfing and molehill/snake are useful for understanding the differences between traditional qualitative and post-qualitative orientations to data and analysis as well as our twenty-first century lived experiences.

\section{Snakes}

As post-qualitative researchers, we understand that we can never "get ahead" of our data just as we can never "get ahead" of a coiling snake. We do not peer into the depths of data or our participants' lives in order to find a complete sequence from bottom to top in a neat hierarchy of events, as one might peer into a molehill. Moreover, post-qualitative researchers question the existence and creation of data. It is not just neutral or given. Data, if one believes that it exists at all, is not just there, grounded, for the researcher to find, stumble upon, or mine as one might discover the molehill that preceded them "the simple empiricism of the phenomenology of conventional humanist qualitative methodology that digs deep into the given" (St. Pierre, 2017, p. 690). The same can be said for methodology. St. Pierre, Jackson \& Mazzei (2016) write that "we are required, in the name of valid, systematic science, to force that experience [wonderings resulting from encounters in the world] into the structure of a pre-existing methodology that simply cannot accommodate it" (p. 104). Hence, if researchers believe that data, findings, and knowledge are there, preexisting them, to find or uncover, pre-existing, pre-packaged methodologies may be sufficient.

Like a snake, data, however one defines it, is slippery, and elusive, and we must be vigilant. Our eyes must be trained to locate and track and follow whatever winding course it may take. Post-qualitative researchers find themselves struck by their data, surprised by it, wondering about it (Maclure, 2013). It sneaks up on them when they least expect it, and when it does, we can never be quite sure of what we are seeing. Still, some encounter with the world jolts us and demands a response, that, as St. Pierre, Jackson \& Mazzei (2016) put it;

sets our curiosity to work; sends us to the library to read hoping to find others intrigued by the same problem; intrudes in our conversations with colleagues ("Have you ever wondered about -?"); saturates that liminal space-time between sleeping and waking; and, eventually, reorients our seeing, re-orients our thinking, re-orients being, so that orthodox distinctions fail, 
normalized boundaries dissolve, and things that are not supposed to relate connect and surge into new intensities (p. 104).

A social world characterized by the constantly-new thus demands a methodology that can respond in kind.

\section{Surfing}

Deleuze (1992) contrasted surfing with sports. Unlike surfing, sports are rule-laden and territorydependent, with specific implements to be utilized in particular ways to produce particular results or outcomes-much like methodology in traditional qualitative research. Lenz-Taguchi \& Palmer (2013) likened their post-qualitative methodology of data-reading, or diffractive analysis, to surfing;

It was these events of engagement with data in the apparatus of knowing that made us physically experience the workings of a diffractive analysis. We felt like surfers taking advantage of 'the diffraction patterns created by the rocks or pieces of land that stick out near the shore/.../literally riding the diffractive patterns, wave after wave in different directions', as Barad writes $(2007,80)$ (p. 675).

Surfing, a oneness between a body and wave, which is ridden, not harnessed, or captured or forced into conformity. The process Lenz-Taguchi and Palmer explain above involved their bodily engagement with the data. They went with the data, surrounded themselves with it "this process felt as if we passed ourselves over to a flow of entangled social, material and discursive forces in the apparatus of knowing, where one text would link, connect or collide with another, and produce something new or different" ( $p$. 675). Waves are continually new and each wave is unique. Thus, each "pass through" with the data produced something new and different. The authors' duty was to stay attuned to these moments.

A surfer, much like a data-reader, must learn to navigate the sea of data and find and use the concepts that will be most helpful for each unique situation. In other words, the rules might be "made up" as one goes along depending on the situation at hand. In this way it is a nomadic, deterritorialized process (Deleuze, 1987/2011).

In a reflection on the heavy work of reading Deleuze, Kennedy (2000/2002) noted Deleuze's ability to make one feel "disoriented...lost in space" and advises; "be patient, learn to go with the flow and the force of his ideas, for they lead to exciting pathways, new territories, vistas, landscapes of silence, solitude but often schizophrenia... [he] taught me never to be fixed, never to be satisfied, never to say 'this is how it is'; for, of course, it never is and never should be" (p. 3). This is good advice not only for learning to learn from Deleuze, but also strategies for survival in control societies. Deleuze is challenging because he is not prescriptive or hierarchal, but rhizomatic and open; an openness leading to new openings and positionalities, or as Zarabadi, Taylor, Fairchild, \& Moxnes (2019) put it, "stringing openings for doing-being in the academy differently" (p. 92). 


\section{Surfing and snakes as survival}

Both surfing and snakes seem particularly suited to explaining the uncertain times we are living in and the ways we are able to live at all. Here in the United States, for example, at the first preparation of this manuscript (October 2017) the Las Vegas concert shooting (September 2017) is already becoming a distant memory even though it happened only a few weeks ago. Every day seems to bring new, increasingly bizarre and troubling news from Washington, D.C. and the Trump presidency. Surfing seems to be the coping mechanism at this point, a way of riding each "wave" of the news cycle and each senseless tragedy with the only guarantee being that another, different "wave" will surely come along and that, too, we will have to ride. As professors in the Southeast United States, two of us work at universities in a state that has legalized guns on campus while simultaneously providing faculty with training for active-shooter situations. Instead of feeling safer, Erin, for example, has feelings of paranoia and fear when working in her office, especially in the evenings (the time of day, she was told by the University's safety officer, that faculty are the most vulnerable).

The hyper surveillance, made possible by the very technological devices that are supposed to free us, makes a snake-like existence appealing. Elude "capture," provoke on the sly, stay low to the ground. Slither, strike, retreat.

Post-qualitative methodologies, such as the kinds of diffractive analysis that Lenz-Taguchi \& Palmer (2013) use, are appropriate and e/affective because they are responsive to the ever-present present of the here and now. Deleuze (1992) wrote that a control society relies on modulation, or affects at the level of the dividual body, a body that is not individual/mass but "masses, samples, data, markets or "banks" undulating within a continuous network (p. 5). The methods used and the phenomena studied/data, in other words, are of the same "regime" of a society of control. Post-qualitative researchers use the tools of the control society in order to make sense of it and push back against it.

\section{Professionalization, openness and the future (of the academy)}

We continue to be impressed by Deleuze's prescience; his ability to describe today's conditions. Deleuze predicted the increasing focus on careers, specialized knowledge and specific monetized "outcomes" of education we are seeing today not only at the K-12 focus on "college and career" development but also, and especially, in academia. In a lecture in 1987 Deleuze said, "even the schools. We should closely watch the themes that develop over the next forty or fifty years. They will explain how wonderful it would be to pursue both school and a profession. It would be interesting to see what the identity of schools and professions will become with constant training, which is our future" (Deleuze, 1987/2007, p. 327). Deleuze was concerned with the effects of perpetual training and the emphasis on "professions," or careers, to the detriment of university research and the "introduction of the 'corporation' at all levels of schooling" (Deleuze, 1992, p. 7). Such professionalization risks churning out methodologists at the expense of theory, hence the tenuous relationship between post-qualitative research and pedagogy, which risks the idea of teachable research methodologies and methods (St. Pierre, Jackson \& Mazzei, 2016, p. 105). As Morrison (1993) relayed in her 1993 Nobel Prize speech; 
There is and will be rousing language to keep citizens armed and arming; slaughtered and slaughtering in the malls, courthouses, post offices, playgrounds, bedrooms and boulevards; stirring, memorializing language to mask the pity and waste of needless death. There will be more diplomatic language to countenance rape, torture, assassination. There is and will be more seductive, mutant language designed to throttle women, to pack their throats like pâtéproducing geese with their own unsayable, transgressive words; there will be more of the language of surveillance disguised as research; of politics and history calculated to render the suffering of millions mute; language glamorized to thrill the dissatisfied and bereft into assaulting their neighbors; arrogant pseudo-empirical language crafted to lock creative people into cages of inferiority and hopelessness.

What Morrison said in the 1990s is exactly what is happening today. Drawing off of this speech, Davies (2005) wrote of neoliberal academic institution "bend[ing] their energies to the bottom line" (p. 4) and academics who "are worthy of respect because they bring in outside money-and what of the value of their work, I ask, but the question draws a blank" (p. 7). Davies' proposed solution was to train students in philosophy so that they can understand how seductive discourses like neoliberalism, or control societies, work.

Yet, even with and in these structures can be found resistances and openings. For example, unsettled by the Institutional Review Board's certainty "about what research was and could become" Slovin and Semenec (2019) found ways to push back and write "outside of the IRB boxes" in conducting research (pp. 18-19). They express a desire to privilege being ethical rather researchers "forcing their projects into a preexisting ethical framework" (p. 25). In another example, Coleman and Osgood (2019) ran world-making workshops using glitter as serious play, the "creation of collective and open-ended work" (p. 68) in thinking about and using glitter and other materials.

The concept of a control society is useful for thinking about the future of the academy and publishing, particularly calls for openness and transparency. Calls for open-access journals and the opening up and mobilisation of the academy through online courses and programs, the reduction of "seat time" and Massive Open Online Courses (MOOCs), for example, are supposed to democratize the institution and provide knowledge freely. They break the hierarchal holding of knowledge in an ivory tower and hand it over to the masses. The poststructuralist project of prying open previously closed structures is to be celebrated. Knowledge that is open, free and accessible sounds unquestionably good. We are not saying it isn't good, but that does not mean that it is also not dangerous. Societies of control, reminds us that we must stop to think; what does this opening open us up to? for? Who or what is watching now that did not before? Who is peering in? What are the latest forms of surveillance? What new mechanisms of control await us in this new regime of freedom? And possibly most importantly, as prompted by Deleuze, we wonder how these societies of control function ontologically. What ways of living in the world do they open up and close down? We don't have answers, only warnings and a bit of hope, as Deleuze reminds us that "there is no need to fear or hope, but only to look for new weapons" (Deleuze, 1992, p. 4). All of this happens in an education system which is opposite of assembly-line logic, relying 
instead on a kind of "liberatory dissasembly" that frees us from some constraints (e.g. cords \& space) while imposing other methods of control such as constant monitoring and surveillance.

\section{"Final" Thoughts?}

In these "experiment[s] in being experimental" (Otterstad and Waterhouse, 2016, p. 748) we have revisited our collective writing archive in order to inquire into how the video was created - the pedagogical decisions and 'cuts' that were made and the social conditions inherent in that making. In doing this, we open up and expose the messiness of a (supposedly) "finished" product while considering what it means to teach and learn within and against control societies. Teachers never know how their work will be taken up by their students and researchers never know how their work will be taken up by their readers. Pedagogues in any context can never be sure of the direction their pedagogy will take or the outcomes it will produce. The question, as it pertains to post-qualitative research, is even more difficult to answer, as such an orientation is notably without handbooks. Books such as Jackson and Mazzei's Thinking with Theory (2012), and Coleman and Ringrose's (2013) Deleuze and Research Methodologies and special issues of journals such as Qualitative Inquiry (2020) and RERM (2019) offer excellent examples of studies that attempt to break the theory/practice divide though not prescriptions or guidelines that tells one what to do and how to do it. Hence, post-qualitative pedagogy in education must remain open enough for researchers to do and think with what they have to work in their sensemaking processes. Our intention has been to expose the labor, messiness, cooperation, and collectivity involved in making a particular pedagogical tool, the $\mathrm{So} C$ video and then to consider the role of the control society and (post)modern technology in making post-qualitative research not only possible, but, perhaps even necessary.

The Three Minute Theory SoC video alongside its archive acts as a mechanism of reflexivity allowing us to demonstrate Deleuze's concept in action, with SoC and its politics of openness theorized as both a condition under which we are able to work but also a dangerous condition to which women and vulnerable populations are particularly at risk. We hope that the creation of the video has provided insight into possibilities for post-qualitative pedagogy that resists the "stratifying" predetermined steps that "stifles curiosity" (St. Pierre, Jackson \& Mazzei, 2016, p. 106). We have also grappled with the conflicting freedoms and constraints that come with such openings, acknowledging that acquiescing to societal demands to "openness" is fraught with its own problems. We hope that SoC can not only be instructive, but writerly, with control societies serving as the social text and conceptual toolbox for postqualitative researchers to do their work with/in.

Pedagogically, the video functions as a "nomadic subject" a "navigational tool" or "figuration" to get through "the tumultuous water of contemporary complexity" that exemplifies [control] society today (Braidotti, 2018). That is, the video is able to navigate the tumult of the world while using those tools of the world (such as the Internet, social media and YouTube). It is able to provide an explanation for a theory that we nonetheless are living. 


\section{References}

Adams, E., Pittard, E. A. \& Kerr, S. (2015, January 18). Three Minute Theory (3MT): What is neoliberalism? Retrieved from https://www.youtube.com/watch?v=dzLv3rfnOVw

Barad, K. (2007). Meeting the universe halfway: Quantum physics and the entanglement of matter and meaning. Durham, N.C.: Duke University Press. https://doi.org/10.1215/9780822388128

Barad, K. (2012). Intra-actions (interview by Adam Kleinman). Mousse, 34, p. 76-81.

Barthes, R. (2002) S/Z. (R. Miller, Trans.). Oxford; Blackwell. (Original work published 1973).

Braidotti, R. (2018). A Critical Europe Can Do It! Interview with Rosi Braidotti. (Interview conducted by Joost de Bloois). In Critical theory at a crossroads: Conversations on resistance in times of crisis (S. De Cauwer, Ed.). (pp. 1-46) New York: Columbia University Press. https://doi.org/10.7312/dec18678-003

Brumberger, E. R. (2007). Making the strange familiar a pedagogical exploration of visual thinking. Journal of Business and Technical Communication, 21(4), 376-401. https://doi.org/10.1177/1050651907304021

Castro, J.C. (2007). Constraints that enable: Creating spaces for artistic inquiry. Proceedings of the 2007 Complexity Science and Education Research Conference (pp.75-86). Vancouver, British Columbia.

Coleman, R. \& Osgood, J. (2019). PhEMaterialist encounters with glitter: the materialisation of ethics, politics and care in arts-based research. Reconceptualizing Educational Research Methodology, 2(3), 61-86. https://doi.org/10.7577/rerm.3669

Coleman, R. \& Ringrose, J. (2014). Deleuze and Research Methodologies. Edinburgh: Edinburgh University Press.

Davies, B. (2005). The (im)possibility of intellectual work in neoliberal regimes. Discourse: studies in the cultural politics of education, 26(1), 1-14. https://doi.org/10.1080/01596300500039310

Davies, B. \& Gannon, S. (Eds.) (2006). Doing collective biography: Investigating the production of subjectivity. Berkshire, U.K.: Open University Press.

deFreitas, E. (2017). Karen Barad's quantum ontology and posthuman ethics: Rethinking the concept of relationality. Qualitative Inquiry, 23(9), 741-748. https://doi.org/10.1177/1077800417725359

Deleuze, G. (1992). Postscript on the societies of control. October, 59, 3-7.

Deleuze, G. (2007). Letter to Uno: How Felix and I worked together. In D. Lapoujade (Ed.) Two regimes of madness: Texts and interviews 1975-1995 (pp.237-240) (A. Hodges \& M. Taormina, Trans.). New York: Semiotext(e). (original work published in 1984).

Deleuze, G. (2007). What is the creative act? In D. Lapoujade (Ed.) Two regimes of madness: Texts and interviews 1975-1995 (pp.317-329) (A. Hodges \& M. Taormina, Trans.). New York: Semiotext(e). (Original lecture given in 1987 \& published in 1998).

Deleuze, G. \& Guattari, F. (2009). Anti-Oedipus: Capitalism and schizophrenia. (R.Hurley, M.Seem, and H.R.Lane, Trans.). New York: Penguin Books. (Original work published 1972).

Deleuze G. \& Guattari, F. (1987). A thousand plateaus: Capitalism and schizophrenia. (Brian Massumi, Trans.) Minneapolis, MN: University of Minnesota Press. (Original work published in 1980).

Foucault, M. (2003). The Essential Foucault: Selections from Essential works of Foucault, 1954-1984. (P. Rabinow, and N. Rose Eds.). New York, NY: The New Press 
The Final Cut?: The Production of Pedagogy and scholarship... 78

Foucault, M. (2008). The birth of biopolitics. (M. Senellart, Ed.; G.Burchell, Trans.).New York: Palgrave MacMillian. (Original work published 2004).

Grosz, E. (1999). Thinking the new: Of futures yet unthought. In Becomings: Explorations in time, memory, and futures (E. Grosz, E. Ed.) (pp. 15-28). Ithaca, NY: Cornell University Press

Housen, A., \& Yenawine, P. (2001). Visual thinking strategies: Understanding the basics. VUE: Visual Understanding in Education.

Jackson, A. Y., \& Mazzei, L. A. (2012). Thinking with theory in qualitative research: Viewing data across multiple perspectives. New York: Routledge.

Jackson, A. Y., \& Mazzei, L. A. (2013). Plugging One Text Into Another Thinking With Theory in Qualitative Research. Qualitative Inquiry, 19(4), 261-271. https://doi.org/10.1177/1077800412471510

Jackson, A. Y., \& Mazzei, L. A. (2012). Thinking with theory in qualitative research: Viewing data across multiple perspectives. New York: Routledge.

Kennedy, B.M. (2002). Deleuze and cinema: The aesthetics of sensation. Edinburgh, Scotland: Edinburgh University Press (original published 2000).

Kerr, S., Adams, E., \& Pittard, E. A. (2015, September 13). Three Minute Theory (3MT): What are societies of control? Retrieved from https://www.youtube.com/watch?v=onZ1U4jKJdk

Lather, P. (2007). Getting lost: Feminist efforts towards at double(d) science. Albany, NY: SUNY Press.

Lather, P. (2013). Methodology-21: What do we do in the afterward? International Journal of Qualitative Studies in Education, 26(6), 634-645. https://doi.org/10.1080/09518398.2013.788753

Lather, P. \& St. Pierre, E.A. (2013). Post-qualitative research. International Journal of Qualitative Studies in Education, 26(6), 629-633. https://doi.org/10.1080/09518398.2013.788752

Lenz Taguchi, H., \& Palmer, A. (2013). A more 'livable' school? A diffractive analysis of the performative enactments of girls' ill-/well-being with(in) school environments. Gender \& Education, 25(6), 671-687. https://doi.org/10.1080/09540253.2013.829909

MacLure, M. (2013). Classification or wonder? Coding as an analytic practice in qualitative research. In Coleman and Ringrose, (Eds.) Deleuze and Research Methodologies (pp.164-183). Edinburgh: Edinburgh University Press

Mazzei, L.A. \& Smithers, L.E. (2020). Qualitative inquiry in the making: A minor pedagogy. Qualitative Inquiry, 26(1), 99-108. https://doi.org/10.1177/1077800419869966

Morrison, T. (1993). Nobel Lecture. https://www.nobelprize.org/prizes/literature/1993/morrison/lecture/

Otterstad, A.M. \& Waterhouse, A. L. (2016). Beyond regimes of signs: Making art/istic portrayals of haptic movements with child/ren/hood. Discourse: Studies in the cultural politics of education, 37(5), 739-753. https://doi.org/10.1080/01596306.2015.1075727

St. Pierre, E. A., Jackson, A. Y., \& Mazzei, L. A. (2016). New Empiricisms and New Materialisms. Cultural Studies/Critical Methodologies, 16(2), 99-110. https://doi.org/10.1177/1532708616638694

St. Pierre, E. A. (2017). Haecceity: Laying out a plane for post-qualitative inquiry. Qualitative Inquiry, 23(9), 686-698. https://doi.org/10.1177/1077800417727764

Three Minute Theory. (n.d.). Videos [YouTube Channel]. Retrieved from https://www.youtube.com/c/ThreeMinuteTheory/videos 
Van Cleave, J. \& Bridges-Rhoades, S. (2013). "As cited in" writing partnerships: The impossibility of authorship in postmodern research. Qualitative Inquiry 19(9), 674-685. https://doi.org/10.1177/1077800413500932

Wurzburg, E. A., Kerr, S., \& Adams, E. (2020, April 25) Theory in the Time of COVID https://www.youtube.com/watch?v=SSVhVYet5LY

Zarabadi, S, Taylor, C.A., Fairchild, N., Moxnes, A.R. (2019). Feeling medusa: Tentacular troubling of academic positionality, recognition and respectability. Reconceptualizing Educational Research Methodology, 2(3), 87-111. https://doi.org/10.7577/rerm.3671 